\title{
Analisis Strategi Pemasaran Untuk Meningkatkan Daya Saing Pada SMA Nusantara Plus Ciputat
}

\author{
Syarif Hidayatullah ${ }^{1}$
}

STIE Ganesha, Email : syarif@stieganesha.ac.id

\section{ARTICLES}

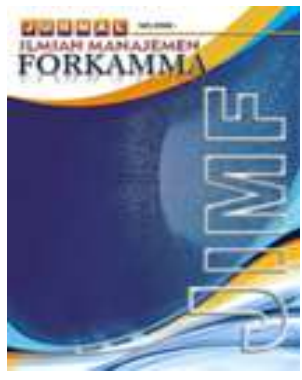

\section{JURNAL ILMIAH MANAJEMEN FORKAMMA}

Vol.4, No.3, Juli 2021

Halaman : $237-250$

(c) LPPM \& FORKAMMA

Prodi Magister Manajemen UNVERSITAS PAMULANG

ISSN (online) : 2599-171X

ISSN (print) : : 2598-9545

\section{Keyword :}

SWOT; Marketing Strategy; Competitiveness

JEL. classification :

O15,

\section{Contact Author : \\ PRODI \\ MAGISTER MANAJEMEN \& FORKAMMA UNPAM \\ JL.Surya Kencana No.1 Pamulang \\ Tangerang Selatan - Banten \\ Telp. (021) 7412566, Fax (021) 7412491 \\ Email : \\ jurnalforkamma.unpam@gmail.com}

Abstrak. Analisis ini dilakukan untuk mengetahui kondisi ineternal dan eksternal sekolah agar dapat menciptakan strategi pemasaran yang tepat dalam meningkatkan daya saing SMA Nusantara Plus. Dengan menggunakan metode analisis deskriptif dan pengumpulan data melalui wawancara langsung dengan pihak sekolah, kemudian data dianalisi menggunakan matriks EFE, IFE, CPM dan SWOT. Hasil analisis menunjukkan bahwa strategi yang paing tepat untuk diimplementasikan oleh manajemen SMA Nusantara Plus Ciputat adalah strategi penetrasi pasar.

Keywords: SWOT; Strategi Pemasaran; Daya Saing

Abstract. This analysis aims to determine the internal and external conditions of the school in order to create the right marketing strategy in increasing the competitiveness of SMA Nusantara Plus. By using descriptive analysis method and data collected by direct interviews with the schools stakeholder, then the data is analyzed using the EFE, IFE, CPM and SWOT matrices. The results of the analysis show that the most appropriate strategy to be implemented by the management of SMA Nusantara Plus Ciputat is the market penetration strategy.

Keywords: SWOT; Marketing strategy; Competitiveness 


\section{A. PENDAHULUAN}

Sekolah bergerak dibidang jasa pendidikan yang mutlak memerlukan strategi pemasaran yang tepat. SMA Nusantara Plus merupakan salah satu dari sekolah menengah atas di wilayah Ciputat yang berdiri pada tahun 2011. Sebagai sekolah yang baru, SMA Nusantara Plus memiliki banyak pesaing dan belum memaksimalkan strategi pemasaran sekolah.

Menurut pendapat Wijaya (2008:42) sebuah lembaga pendidikan nonprofit tetap mutlak membutuhkan strategi dalam pemasarannya. Hal ini disebabkan beberapa hal antara lain lembaga pendidikan merupakan sebuah lembaga sosial yang bergerak dibidang jasa pendidikan perlu untuk memberikan keyakinan kepada masyarakat atau peserta didik bahwa lembaga tersebut dalam kondisi yang eksis dan dapat meyakinkan masyarakat bahwa lembaga tersebut mampu menyediakan layanan pendidikan yang sesuai dengan kebutuhan masyarakat. Selanjutnya Lembaga harus melaksanakan kegiatan pemasaran guna tujuan, visi dan misi sekolah diketahui secara luas oleh masyarakat serta meningkatkan eksistensi lembaga pendidikan di benak pelanggan potensial dan hal ini tidak hanya dikenal sebagai kegiatan pemasaran saja namun lebih merupakan suatu bentuk tanggung jawab kepada masyarakat luas.

Marketing Pendidikan belum begitu populer dikalangan masyarakat awam, sehingga mereka khawatir Lembaga tersebut akan menjadi kkomersil. Hal ini wajar saja karena Lembaga Pendidikan biasa dikenal dengan organisasi nonprofit. Berbeda dengan komersial atau proft oriented oagnization yang sudah jelas mengejar laba atau keuntungan. Lembaga Pendidikan diketahui secara luas sebagai organisasi yang menyediakan layanan konsumen kepada siswa, mahasiswa dan juga masyarakat umum yang dikenal dengan "stakeholder". Pada dasarnya tujuan dari Lembaga Pendidikan hanyalah memberikan layanan. Dengan demikian marketing jasa pendidikan bertujuan untuk memberikan layanan atau menyampaikan jasa pendidikan kepada konsumen dengan cara yang memuaskan. Hal tersebut dapat kita lihat pada tahun ajaran baru saat - saat penerimaan siswa sekolah dibuka kita kerap menemukan iklan-iklan dari perguruan tinggi swasta, sekolah - sekolah swasta dan negeri pada surat kabar, radio, selebaran cetak, brosur dan spanduk di pinggir jalan dan dikampus. Tujuannya tidak lain adalah untuk menarik perhatian calon siswa atau peserta didik. Fenomena ini dikenal dengan marketing Pendidikan. Marketing Pendidikan memiliki etika yang sangat menghindari karakter yang tidak baik, dan mengharapkan lembaga pendidikan menawarkan mutu layanan intelektual dan pembentukan watak secara menyeluruh (Alma, 2008: 30).

Dalam kehidupan modern dewasa ini, lembaga pendidikan mengahadapi persaingan yang sangat ketat sehingga terkadang melupakan tujuan dan hakekat dari Lembaga Pendidikan itu sendiri yang menjunjung tinggi nilai dan norma dalam masyarakat dan agama.

Hal inilah yang melatarbelakangi terbentuknya lembaga Yayasan Aldiana Nusantara (YAN) yang memiliki tujuan untuk memberikan pendidikan dan membekali putra-putri kita dengan pendidikan yang berkonsentrasi penuh dalam pembentukan akhlakul karimah dan bernuansakan Islami. Yayasan Aldiana Nusantar (YAN) menjembatani hal tersebut di atas dengan mendirikan lembaga pendidikan, yaitu Sekolah Menengah Atas (SMA) Nusantara Plus yang memiliki materi pembelajaran dengan mengkolaborasikan kurikulum diknas dan depag, sehingga diharapkan dapat membekali lulusan SMA Nusantara Plus selain dalam bidang keilmuan umum juga keilmuan bidang keagamaan serta keterampilan.

Berikut adalah data jumlah siswa SMA Nusantara Plus dari tahun 2011 sampai tahun 2019. 


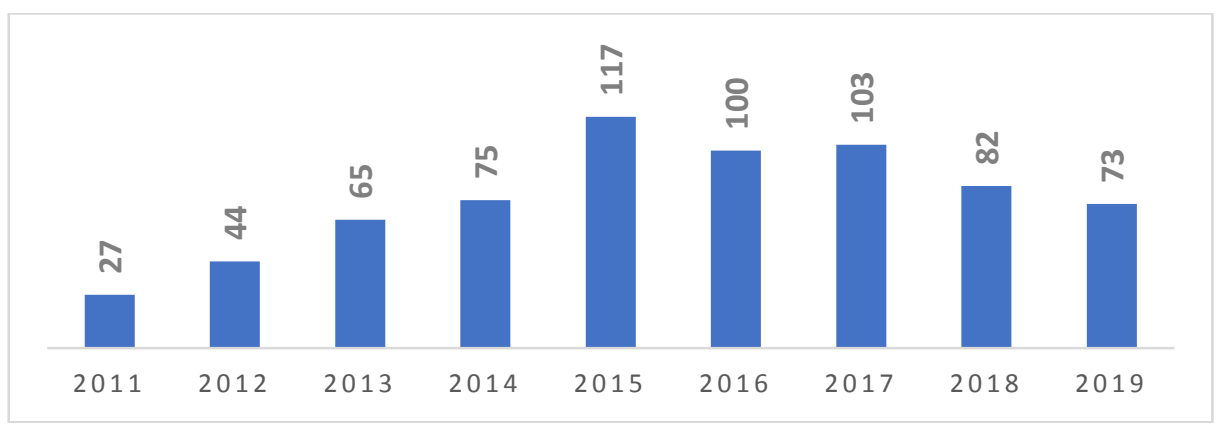

\section{Gambar 1 Grafik jumlah siswa SMA Nusantara Plus Tahun 2011 - 2019}

Grafik diatas menunjukkan bahwa jumlah siswa SMA Nusantara Plus terus terjadi peningkatan dari tahun 2011 sampai dengan tahun 2015. Namun sejak tahun 2016 sampai dengan tahun 2019 mengalami penurunan, walaupun terjadi peningkatan pada tahun 2017 namun tidak signifikan. Saat ini strategi pemasaran yang digunakan SMA Nusantara Plus dalam melakukan pemasaran hanya menggunakan media brosur dan belum memanfaatkan media iklan yang lain serta media elektronik.

\section{B. KAJIAN LITERATUR}

\section{Strength, Weakness, Opportunities and Threats (SWOT) ANALISIS}

Menurut Freddy Rangkuti (2013) adalah Analisis yang berdasarkan kepada logika dalam mengidentifikasi berbagai faktor dengan sistemtis guna merumuskan strategi yang tepat bagi perusahaan dengan cara mengoptimalkan kekuatan (sterngths) dan peluang (opportunities), mengendalikan dan mengelolah kelemahan (weaknesses) dan ancaman (threats).

\section{Strategi Pemasaran}

Menurut Kotler dan Keller dalam (Lesmana, November 2019) "Strategi pemasaran adalah logika pemasaran dimana perusahaan berharap untuk menciptakan nilai pelanggan dan mencapai hubungan yang saling menguntungkan. Positioning dan strategi diferensiasi perusahaan harus berubah seiring dengan berubahnya produk, pasar, dan pesaing berubah sepanjang siklus produk". Empat hal tentang siklus sebuah produk:

1. Produk mempunyai usia yang terbatas

2. Penjualan produk melalui tahap yang berbeda

3. Laba naik turun pada berbagai tahap

\section{Daya Saing}

Daya saing menurut Porter dalam (Wardani, 2017) ialah "kemampuan suatu organissasi untuk memasuki pasar dan mampu bertahan didalam pasar tersebut. Jika suatu produk mempunyai daya saing maka produk tersebut akan diminati oleh konsumen. Menurut Porter (1990), keunggulan daya yang menentukan saing suatu komoditi dikelompokkan menjadi dua macam, yaitu keunggulan alamiah/keunggulan absolut (natural advantage) dan keunggulan yang dikembangkan (acquired advantage). Pendekatan yang sering digunakan untuk mengukur daya saing komoditi adalah faktor 
keunggulan komparatif (comparative advantage) dan faktor keunggulan kompetitif (competitive advantage)".

\section{B. METODOLOGI PENELITIAN}

Jenis penelitian ini adalah kualitatif dengan meggunakan pendekatan deskriptif, metode deskriptif yaitu suatu metode penelitian yang memiliki tujuan untuk memberikan penjelasan atau gambaran secara mendetail, berurutan, faktual dan akurat mengenai fakta-fakta, sifat-sifat serta hubungan antar fenomena yang diselidiki (Nazir, Moh. (2005, p54)).

Variabel dalam penelitian ini yaitu lingkungan internal dan eksternal, strategi pemasaran dan daya saing. Yang termasuk dalam lingkungan internal berupa faktorfaktor dari dalam sekolah yang dapat mempengaruhi aktivitas sekolah. Lingkungan internal dipengaruhi oleh kekuatan dan kelemahan, sedangkan lingkungan eksternal dipengaruhi oleh peluang dan ancaman.

Objek analisis pada penelitian ini adalah sekolah SMA Nusantara Plus. Pengumpulan data berupa data primer dan data sekunder. Data primer yaitu berupa informasi yang didapatkan secara langsung dari wawancara dan pengajuan kuesioner kepada pihak internal sekolah untuk mendapatkan informasi yang diperlukan untuk penelitian.

Alat analisis yang dipergunakan untuk mengetahui faktor internal dan eksternal guna perumusan marketing strategi yang tepat bagi SMA Nusantara Plus adalah analisis SWOT. Analisis SWOT dilakukan dengan mengidentifikasi apa saja kekuatan dan kelemaha, peluang dan ancaman yang dihadapi secara mendalam dan detail sehingga dapat memformulasikan marketing strategi sekolah yang tepat dalam memaksimalkan kekuatan dan peluang, mengendaikan dan mengelolah kelemahan dan kekuatan. Marketing strategi dirumuskan dari hasil Matriks SWOT, Matriks SPACE, Matriks IE, Matrix Grand strategy yang kemudian dilanjutkan ke dalam QSPM untuk merumuskan strategi akhir yang tepat bagi sekolah. Untuk melakukan pembobotan pada matriks IFE, Matriks EFE dan Matriks CPM digunakan software expert choice. Expert choice menggunakan metode pairwise comparison (perbandingan berpasangan) untuk pembobotan.

Objek analisis adalah stakeholder SMA Nusantara Plus Ciputat, JI. Tarumanegara Dalam No.1, Pisangan, Kec. Ciputat Tim., Kota Tangerang Selatan, Banten 15419

Teknik perumusan strategi yang penting dapat dipadukan menjadi suatu kerangka kerja pembuatan keputusan yang terdiri dari tiga tahap, yaitu tahap input, tahap pencocokan, dan tahap keputusan. Dimana lebih jelasnya pada gambar sebagai berikut:

Tabel 1 Kerangka Kerja

\begin{tabular}{|ccc|}
\hline & A. TAHAP PENGUMPULAN DATA \\
Matriks EFE & Matriks IFE & Matriks CPM \\
& & \\
Matriks SWOT & Matriks IE & Matriks SPACE Matriks Strategi Besar \\
& & \\
\hline
\end{tabular}




\section{HASIL DAN PEMBAHASAN}

Analisis SWOT pada SMA Nusantara Plus Ciputat:

Tabel 2 Peluang SMA Nusantara Plus

Peluang Eksternal SMA Nusantara

O1. Kesadaran masyarakat untuk mendapatkan pendidikan yang layak

O2.Lokasi sekolah berada di wilayah pendidikan

O3.Indonesia memiliki potensi jasa pendidikan yang tinggi

O4.SMA Nusantara berdiri dibawah naungan Yayasan Aldiana Nusantara

O5.Banyaknya investor yang tertarik pada institusi pendidikan

Sumber: SMA Nusantara

Tabel 3 Ancaman SMA Nusantara Plus

Ancaman Eksternal SMA Nusantara

T1. Adanya potensi jasa pendidikan pengganti

T2. Banyak pesaing utama di wilayah Ciputat Timur

T3. Potensi masuknya pesaing baru sangat besar

T4. Semakin canggih nya teknologi semakin menuntut standarisasi yang tinggi

T5. Peraturan pemerintah yang sering berubah-ubah

Sumber: SMA Nusantara

Tabel 4 Kekuatan SMA Nusantara Plus

Kekuatan Internal SMA Nusantara

S1. Lokasi sekolah yang strategis

S2. Biaya pendidikan yang telatif terjangkau

S3. Fasilitas sekolah yang memadai

S4. Sudah terakreditasi (A)

S5. Bernuansakan Islam

Sumber: SMA Nusantara

Tabel 5 Kelemahan SMA Nusantara Plus

Kelemahan Internal SMA Nusantara

W1. Lingkungan belajar yang kurang kondusif

W2. Sekolah baru berdiri selama 4 tahun 
W3. Promosi yang dilakukan belum maksimal

W4. Kurangnya SDM dalam bidang pemasaran

W5. Belum melokalisasikan beberapa fasilitas sekolah

Sumber: SMA Nusantara

\section{Tabel 6 Faktor Penentu Keberhasilan dalam CPM pada SMA Nusantara}

\begin{tabular}{|l|}
\hline Faktor Penentu keberhasilan dalam CPM \\
\hline CP1. Pemilihan lokasi \\
\hline CP2. Daya saing harga \\
\hline CP3. Pelayanan \\
\hline CP4. Ketenagakerjaan \\
\hline CP5. Iklan \\
\hline CP6. Referensi Pelanggan \\
\hline CP7. Pengalaman Manajemen \\
\hline CP8. Pangsa Pasar \\
\hline CP9. Loyalitas Konsumen \\
\hline CP10. Posisi Keuangan \\
\hline
\end{tabular}

Sumber: SMA Nusantara

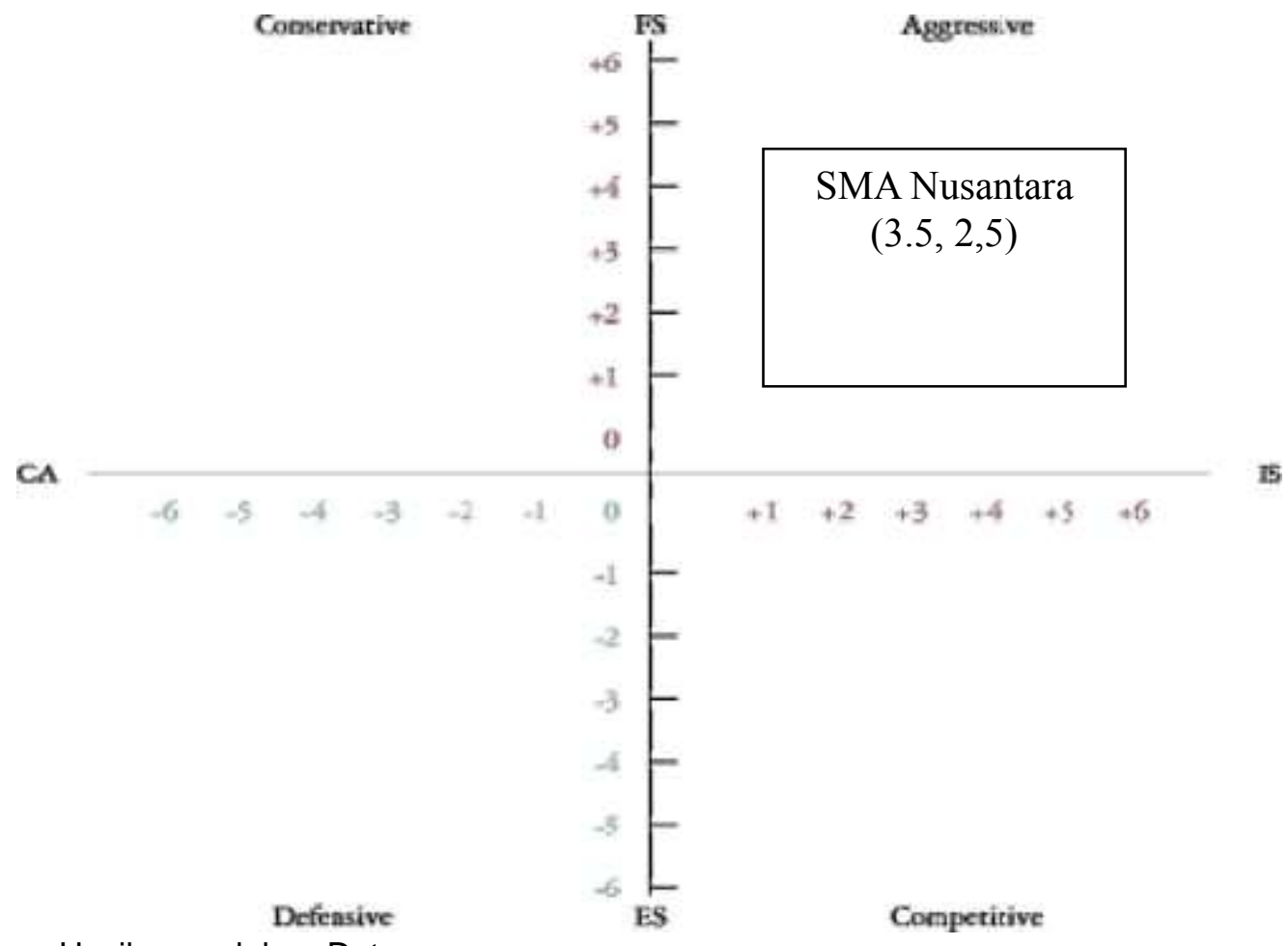


Dari hasil perhitungan matriks SPACE di atas, sumbu x sebesar 3.5 dan sumbu y sebesar 2,5, maka dapat disimpulkan bahwa SMA Nusantara terletak pada posisi kuadran agresif. "Alternatif strategi pada kuadran agresif adalah" :

1. Integrasi ke belakang

2. Integrasi ke depan

3. Integrasi horizontal

4. Penetrasi pasar

5. Pengembangan pasar

6. Pengembangan produk

7. Diversifikasi (terkait atau tak terkait)

Matriks Internal - Eksternal (IE)

Matriks ini bertujuan untuk mendapatkan suatu strategi pemasaran dengan mengacu kepada total score dari faktor internal (IFE) dan faktor eksternal (EFE) perusahaan. Berdasarkan faktor internal SMA Nusantara memperoleh nilai 3,1732 dan nilai faktor eksternal sebesar 3,2762.

\begin{tabular}{|ccc|}
\hline \multicolumn{3}{|c|}{ TOTAL NILAI IFE YANG DIBERI BOBOT } \\
\hline Kuat & Rata-Rata & Lemah \\
$3,0-4,0$ & $2,0-2,99$ & $1,0-1,99$
\end{tabular}

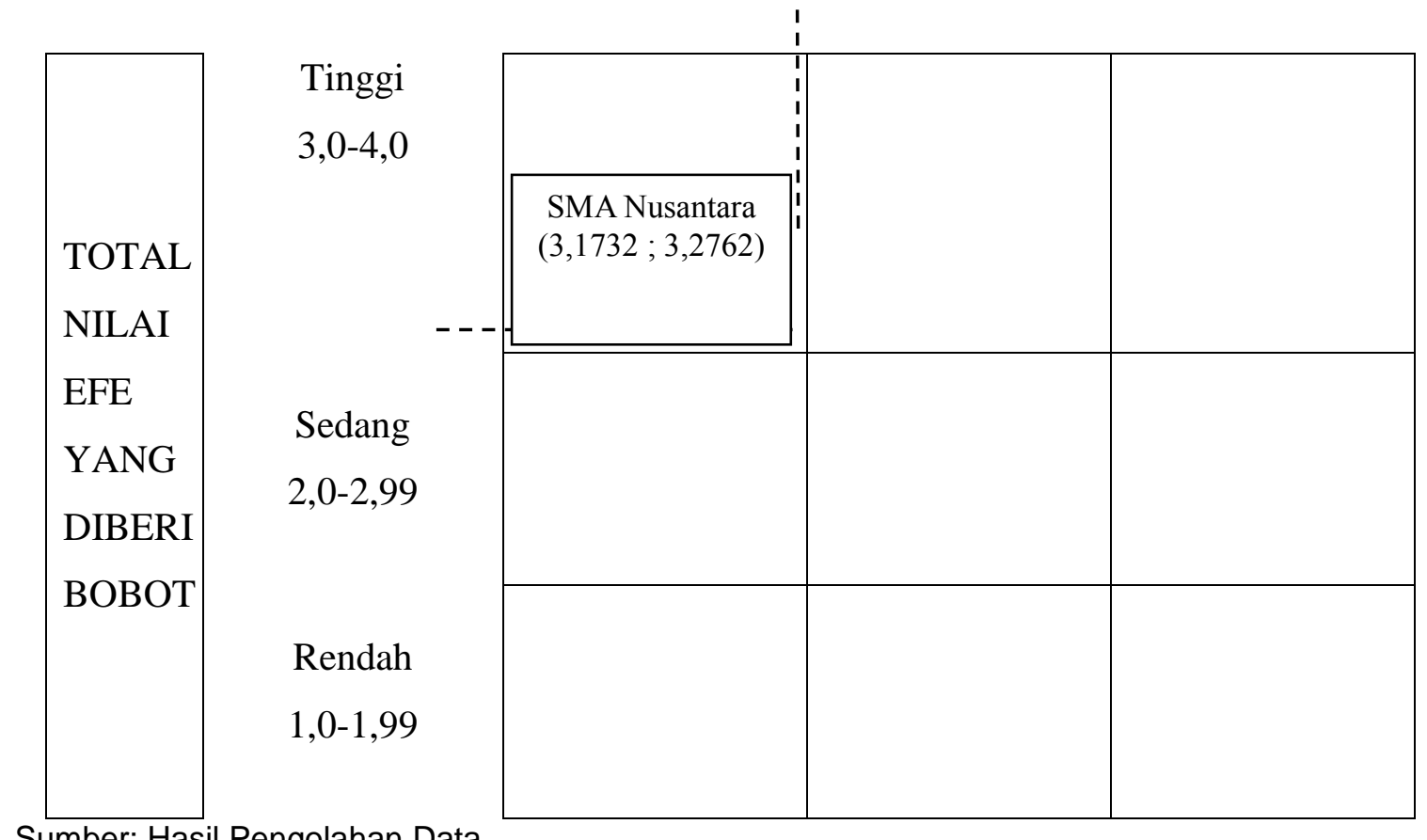

Sumber: Hasil Pengolahan Data

\section{Gambar 2 Matriks IE SMA Nusantara}

Berdasarkan hasil dari Tabel Matriks IFE (Tabel 4.13) dan Tabel Matriks EFE (Tabel 4.12), diketahui bahwa nilai IFE adalah sebesar 3,1732dan nilai EFE adalah sebesar 3,2762. Dengan demikian dapat dilihat bahwa SMA Nusantara berada dalam sel I, yaitu pada divisi tumbuh dan membangun. Dimana dalam divisi ini, ada beberapa alternatif strategi yang dapat dijalankan oleh sekolah, diantaranya: 
- Strategi Intensif (Penetrasi Pasar, Pengembangan Pasar, Pengembangan Produk).

- Strategi Integratif (Integrasi ke Depan, Integrasi ke Belakang, Integrasi Horizontal)

Berdasarkan hasil analisis Matriks Internal - Eksternal (IE), maka SMA Nusantara berada di sel I. Pada sel I strategi yang paling cocok dikelola dengan strategi tumbuh dan membangun, posisi sekolah cukup baik dan daya tarik sedang tumbuh. SMA Nusantara sebaiknya menjalankan strategi intensif.

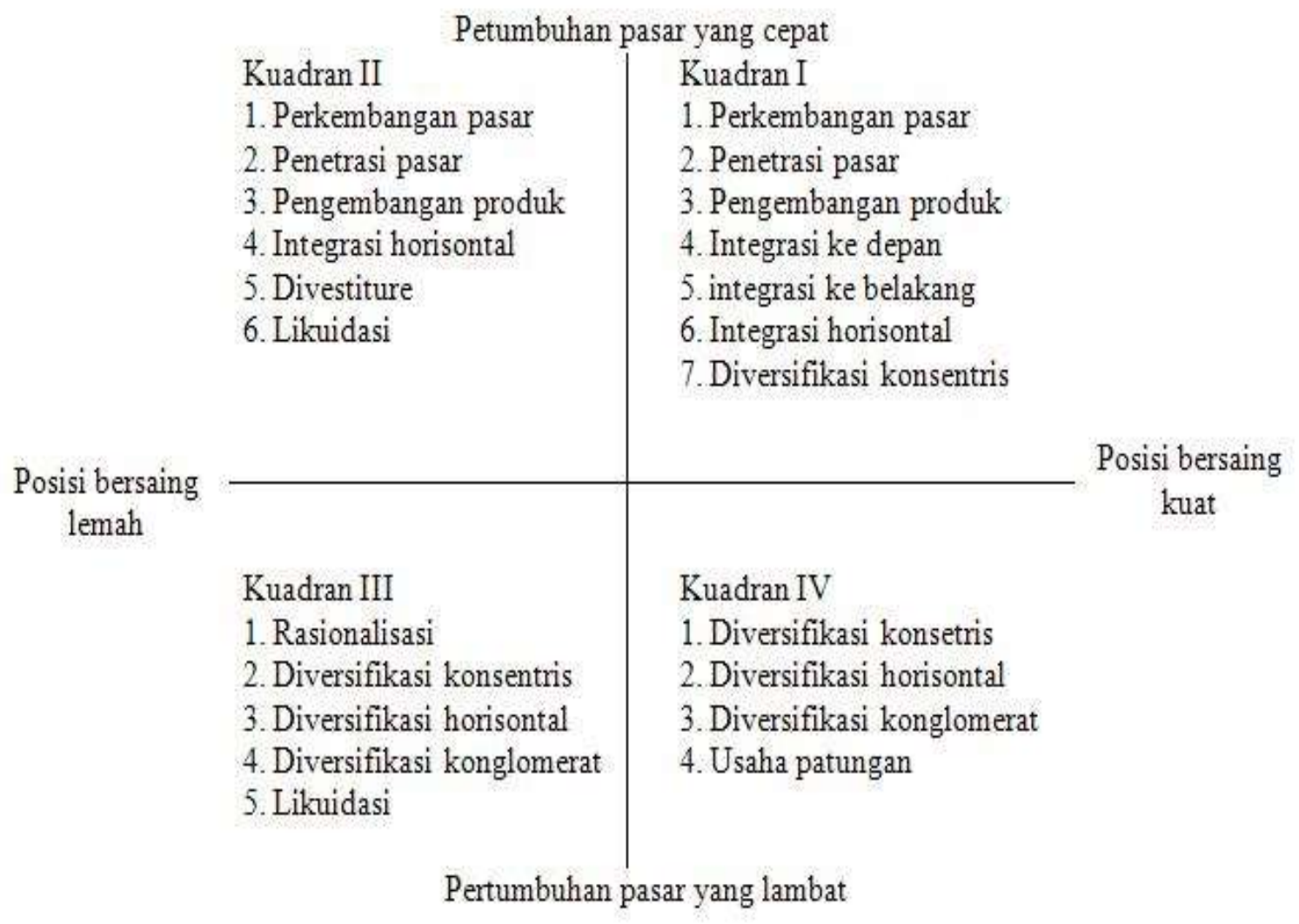

Gambar 3 Matriks Strategi Besar (GrandStrategy Matrix)

Berdasarkan hasil dari tabel matriks CPM, diketahui nilai CPM SMA Nusantara sebesar 3,2312, SMA Darussalam sebesar 2,779, dan SMA Dua Mei sebesar 32856. Nilai CPM SMA Nusantara lebih kecil dari pada SMA Dua Mei, namun lebih besar dari pada SMA Darussalam.

Maka dari itu SMA Nusantara berada di Kuadran II. Bagi organisasi atau perusahaan yang berada pada posisi di Kuadran II ini dituntut untuk lebih detail lagi dalam mengkoreksi strategi pendekatan pasar sasarannya. Meskipun kondisi industri tersebut pada tingkat sedang bertumbuh, mereka belum bisa menghadapi persaingan secara efektif, mereka juga dituntut untuk menggali info mengapa strategi pendekatan pasar saat ini belum efektif dan maksimal dan mengetahui cara untuk meningkatkan daya saing sekolah. Sehingga strategi Intensif sangat tepat bagi organisasi atau Lembaga sekolah yang berada pada posisi Kuadran II, hal ini dikrenakan industri dengan ini memilki pasar yang bertumbuh pesat, strategi insentif (sebagaimana kebalikan dari strategi integratif atau diversifikasi) menjadi pilihan yang tepat. Meskipun begitu, organisasi atau sekolah harus memiliki memilki kompetensi khusus atau keunggulan kompetitif, sebagai alternatif strategi dapat pula mempertimbangkan strategi integrasi horizontal. Divestasi atau likuidasi dapat dipertimbangkan sebagai strategi berikutnya. Penyediaan dana yang 
mungkin dibutuhkan dalam mengakuisisi bisnis lain dan membeli saham digunakan strategi Divestasi.

\section{E. KESIMPULAN}

Berdasarkan hasil penelitian dan hasil analisa pengolahan data, dapat disimpulkan hal-hal sebagai berikut:

1. Kondisi lingkungan internal pada SMA Nusantara adalah:

Kekuatan (Strengths):

- Lokasi sekolah yang strategis

- Biaya pendidikan yang telatif terjangkau

- Fasilitas sekolah yang memadai

- Sudah terakreditasi $(\mathrm{A})$

- Bernuansakan Islam

Kelemahan (weakness):

- Lingkungan belajar yang kurang kondusif

- Sekolah baru berdiri selama 4 tahun

- Promosi yang dilakukan belum maksima

- Kurangnya SDM dalam bidang pemasaran

- Belum melokalisasikan beberapa fasilitas sekolah

Skor rata-rata pada matriks IFE SMA Nusantara yaitu senilai 3,1732; menunjukkan bahwa SMA Nusantara berada pada posisi diatas nilai rata - rata semua kekuatan internalnya.

2. Kondisi lingkungan eksternal pada SMA Nusantara adalah:

Peluang (Opportunities):

- Kesadaran masyarakat untuk mendapatkan pendidikan yang layak

- Lokasi sekolah berada di wilayah pendidikan

- Indonesia memiliki potensi jasa pendidikan yang tinggi

- SMA Nusantara berdiri dibawah naungan Yayasan Aldiana Nusantara

- Banyaknya investor yang tertarik pada institusi pendidikan Ancaman (Threats):

- Adanya potensi jasa pendidikan pengganti

- Banyak pesaing utama di wilayah Ciputat Timur

- Potensi masuknya pesaing baru sangat besar

- Semakin canggih nya teknologi semakin menuntut standarisasi yang tingg

- Peraturan pemerintah yang sering berubah-ubah

Skor rata - rata terhitung pada matriks EFE SMA Nusantara yaitu senilai 3,2762; menunjukkan bahwa SMA Nusantara berada pada posisi maksimal guna "memanfaatkan peluang dan meminimalisir ancaman yang ada di dalam industri".

3. Melalui hasil analisis matriks QSPM pada tahap keputusan (Decision Stage), diketahui total nilai daya tarik strategi untuk melakukan penetrasi pasar sebesar 20,0266 , strategi pengembangan produk / jasa sebesar 17,1406 , strategi integrasi horizontal sebesar 6,529, dan strategi pengembangan pasar sebesar 9,2414. Sehingga dapat disimpulkan bahwa strategi penetrasi pasar lebih menarik untuk diterapkan pada SMA Nusantara.

\section{Saran}

Saran strategi pemasaran yang sebaiknya diterapkan SMA Nusantara adalah strategi penetrasi pasar. Berikut ini adalah tindakan yang dapat dilakukan SMA Nusantara:

Dalam bidang pemasaran, langkah nyata yang dapat dilakukan SMA Nusantara adalah: 
1. Bagian pemasaran akan melaksanakan riset pemasaran secara teratur. "Riset pemasaran adalah kegiatan penelitian di bidang pemasaran yang dilakukan secara sistematis, ditujukan untuk masukan bagi pihak manajemen. Sehingga sekolah dapat mengidentifikasi dan menganalisis masalah-masalah yang berkaitan dengan pemasaran dan hasil yang diperoleh dapat digunakan sebagai bahan pertimbangan untuk membuat keputusan dalam mengevaluasi performa sekolah".

2. "Menjaga dan meningkatkan kualitas yang dimiliki oleh sekolah. Terus berupaya memenuhi spesifikasi jasa yang dibutuhkan calon siswa. Dengan begitu akan tercipta image sekolah yang baik di mata para calon siswa. Image yang baik akan dibawa oleh kekuatan Word of Mouth yang dapat memberikan alasan supaya semua orang lebih mudah dan lebih suka membicarakan jasa dari sekolah".

3. "Menggencarkan internet marketing. Perkembangan jaman yang semakin canggih, sebaiknya SMA Nusantara membuat website dan blog resmi yang di buat oleh sekolah.Walaupun target pasar dari SMA Nusantara adalah kalangan menengah kebawah, akan tetapi kesadaran akan penggunaan internet akan semakin maju. Membuat tim khusus yang bertugas meng-update website dan blog yang dapat menjadi salah satu pilihan dalam rangka menggencarkan internet marketing serta aktif dalam social media seperti Facebook, Instagram, Twitter, dll. Sekaligus agar dapat membangun image kepada masyarakat luas dan dapat membangun target pasar baru untuk sekolah".

4. "Menggunakan alat pemasaran jasa pendidikan meliputi brosur, surat kabar, periklanan atau website sekolah yang mendukung aktivitas pemasaran jasa pendidikan. Pemasaran jasa pendidikan lebih dari aktivitas dan alat pemasaran jasa pendidikan karena merupakan cara berpikir (mindset)".

5. "Aktif mengikuti berbagai event terkait yang sering diselenggarakan. Hal tersebut berguna untuk memperkenalkan jasa yang ditawarkan oleh sekolah kepada masyarakat agar mudah diingat. Dari event tersebut akan banyak calon siswa tertarik untuk bersekolah di SMA Nusantara".

6. Membuat brosur yang lebih menarik. Karena sekolah menggunakan brosur, sebaiknya sekolah men-design brosur yang lebih menarik untuk dilihat oleh calon siswa. Contohnya dengan menampilkan informasi SMA Nusantara, seperti fasilitas yang ada dan ekstrakurikuler yang menjadi nilai tambah sekolah. Memberikan konsep atau nuansa baru di setiap brosur juga penting untuk menarik calon siswa melihat brosur tersebut.

Strategi promosi jasa pendidikan :

a. Mengelola janji tentang jasa pendidikan. Pengelolaan janji tentang jasa pendidikan berarti mengkorrdinasikan janji yang dibuat seluruh sumber daya pemasaran jasa pendidikan eksternal secara interaktif untuk memastikan bahwa janji itu tepat dan layak. Oleh karena itu, ada empat strategi khusus untuk pengelolaan janji tentang jasa pendidikan, yaitu :

1. Menciptakan komunikasi pemasaran jasa pendidikan secara efektif;

2. Mengkoordinasikan komunitas eksternal pemasaran jasa pendidikan;

3. Membuat janji yang realistis;

4. Menawarkan jaminan jasa pendidikan.

b. Mengelola harapan pelanggan jasa pendidikan. Strategi yang dapat dilakukan sekolah untuk memenuhi harapan pelanggan jasa pendidikan, yaitu:

1. Menawarkan pilihan;

2. Menciptakan penawaran jasa pendidikan dengan nilai yang bertingkat;

3. Mengkomunikasikan kriteria dan tingkat efektivitas jasa pendidikan;

4. Merundingkan harapan yang tidak realistis. 
c. Meningkatkan tingkat pendidikan dari pelanggan jasa pendidikan. Pelanggan jasa pendidikan harus menjalankan perannya secaara tepat agar proses penyampaian jasa pendidikan menjadi efektif. Apabila pelanggan jasa pendidika tidak menjalankan perannya maka akan terjadi ketidakpuasan pelanggan jasa pendidikan. Metode komunikasi pemasaran jasa pendidikan yang efektif dapat berupa tingkat pendidikan dari pelanggan jasa pendidikan. Empat pendekatan yang digunakan untuk meningkatkan tingkat pendidikan dari pelanggan jasa pendidikan, yaitu:

1. Mempersiapkan pelanggan jasa pendidikan dalam proses jasa pendidikan;

2. Memastikan standar dan harapan kinerja jasa pendidikan;

3. Menjelaskan harapan setelah penjualan produk jasa pendidikan;

4. Mengajarkan pelanggan jasa pendidikan untuk menghindari permintaan jasa pendidikan ketika volumenya tinggi dan mencari permintaan jasa pendidikan ketika volumenya rendah.

1. Mengelola komunikasi pemasaran internal jasa pendidikan. Komunikasi pemasaran internal jasa pendidikan dapat berupa:

1. Komunikasi vertikal pemasaran jasa pendidikan, yaitu komunikasi yang dilakukan ke bawah (dari pemimpin sekolah sampai dengan guru dan karyawan sekolah) serta komunikasi yang dilakukan ke atas (dari guru dan karyawan sekolah sampai dengan pemimpin sekolah);

2. Komunikasi horizontal pemasaran jasa pendidikan, yaitu komunikasi yang melintas batasan fungsional organisasi sekolah.

Ada empat strategi pengelolaan komunikasi pemasaran internal jasa pendidikan, yaitu:

a. Menciptakan komunikasi vertikal pemasaran jasa pendidikan secara efektif;

b. Menciptakan komunikasi horizontal pemasaran jasa pendidikan secara efektif;

c. Menyamaratakan kedudukan karyawan di kantor sekolah dengan karyawan pendukung sekolah terhadap pelanggan eksternal sekolah melalui interaksi atau pengukuran;

d. Menciptakan tim kerja sekolah lintas fungsi.

Sumber Daya Manusia

1. Sekolah membutuhkan strategi SDM jasa pendidikan untuk memastikan bahwa karyawan sekolah mau dan mampu menyampaikan kualitas jasa pendidikan bahkan tetap termotivasi untuk berorientasi pelanggan jasa pendidikan. Untuk membangun budaya sekolah yang berorientasi pada pelanggan jasa pendidikan dan karyawan sekolah yang berorientasi melayani, sekolah seharusnya mengikuti empat strategi utama berikut ini:

Mempekerjakan karyawan yang tepat. Tahap pertama yang dilakukan sekolah adalah memperkerjakan dan merekrut karyawan sekolah yang tepat. Oleh karena itu, pemimpin sekolah akan berfokus pada praktik rekrutmen karyawan sekolah secara efektif berdasarkan pelatihan teknis, setifikasi, dan keahlian yang dimiliki karyawan sekolah. Untuk mencapai proses perekrutan karyawan sekolah secara efektif agar dapat mencari karyawan sekolah yang tepat, ada tiga cara yang dapat ditempuh, sebagai berikut.

Bersaing untuk mencari karyawan sekolah terbaik, dengan mengidentifikasi calon karyawan sekolah terbaik dan bersaing dengan sekolah yang lain untuk merekrutnya, mewawancarai calon karyawan sekolah pada setiap posisi yang dibutuhkan, dan meningkatkan standar perekrutan karyawan sekolah guna mengidentifikasi karyawan sekolah yang lebih berkualifikasi.

Mempekerjakan karyawan sekolah yang memiliki kompetensi dan kecenderungan untuk melayani pelanggan jasa pendidikan, dengan mewawancarai dan menyeleksi calon karyawan sekolah terbaik dari calon karyawn sekolah potensial. Oleh karena itu, calon karyawan sekolah harus memiliki dua kemampuan utama, yaitu: 
Kompetensi untuk melayani pelanggan, yaitu keahlian dan pengetahuan yang dibutuhkan untuk melakukan pekerjaan yang dapat dilihat dari gelar dan sertifikasi tertentu yang dimiliki calon karyawan sekolah;

Kecenderungan untuk melayani pelanggan, yaitu ketertarikan calon karyawan sekolah untuk melakukan pekerjaan yang berkaitan dengan pelayanan pelanggan jasa pendidikan, yang dapat dilihat dari perilaku dan orientasinya untuk melayani pelanggan jasa pendidikan serta pekerjaan lainnya.

Berusaha menjadi atasan yang disukai karyawan sekolah, yaitu menjadi atasan yang disukai oleh karyawan sekolah, memberikan pelatihan, peluang kerja dan peningkatan karier, dukungan internal yang memadai, insentif yang menarik, serta menawarkan produk jasa pendidikan yang berkualitas sehingga karyawan sekolah bangga terhadap sekolahnya.

2. Mengembangkan karyawan untuk menyampaikan kualitas jasa. Dalam rangka menumbuhkan dan memelihara karyawan sekolah yang berorientasi pada pelanggan jasa pendidikan dan berfokus pada proses penyampaian kualitas jasa pendidikan, sekolah seharusnya mengembangkan karyawannya untuk menyampaikan kualitas jasa pendidikan dengan baik. Oleh karena itu, ada tiga hal penting yang perlu dilakukan, sebagai berikut.

1. Melatih karyawan sekolah sehingga memiliki keterampilan teknis dan interaksi, dengan merancang pelatihan tentang keterampilan, pengetahuan teknis, dan keterampilan interaksi sehingga karyawan sekolah dapat melayani pelanggan jasa pendidikan dengan sopan santun, peduli, tanggap, serta empati sesuai sasaran dan strategi sekolah.

2. Memberdayakan karyawan sekolah, dengan memberikan keterampilan, peralatan, dan otoritas kepada karyawan sekolah untuk melayani pelanggan jasa pendidikan, bergantung pada strategi pemasaran jasa pendidikan, kedekatan dengan pelanggan jasa pendidikan, teknologi pendidikan yang tersedia, lingkungan sekolah, dan jenis kebutuhan karyawan sekolah.

3. Memajukan kerja tim di sekolah, dengan mensosialisasikan slogan "setiap orang di sekolah adalah pelanggan jasa pendidikan", serta menentukan sasaran tim dan penghargaan yang akan diterima tim berdasarkan prestasi dan kinerja tim yang telah dicapai.

3. Menyediakan berbagai sistem pendukungan yang dibutuhkan. Untuk bekerja secara efisien dan efektif, karyawan sekolah memerlukan sistem pendukungan internal sejalan dengan kebutuhannya agar berorientasi pada pelanggan jasa pendidikan. Sistem pendukungan internal sama pentingnya dengan keterampilan dan kompetensi yang dimiliki karyawan sekolah untuk berhubungan dengan pelanggan jasa pendidikan. Oleh karena itu, ada tiga strategi penting yang perlu kita perhatikan agar dapat menjalankan sistem dukungan internal berbasis pelanggan jasa pendidikan, sebagai berikut.

1. Mengukur kualitas jasa pendidikan secara internal, dengan mengukur persepsi pelanggan jasa pendidilan pada kualitas jasa pendidikan secara internal melalui audit layanan pelanggan dan jaminan kualitas jasa pendidikan secara internal.

2. Menyediakan teknologi dan peralatan yang mendukung, dengan menyediakan teknologi dan peralatan pendidikan yang tepat sesuai dengan lingkungan kerja sekolah dan rancangan sistem pekerjaan karyawan sekolah.

3. Mengembangkan proses internal berbasis jasa pendidikan, dengan merancang proses internal berdasarkan nilai-nilai dan kepuasan pelanggan jasa pendidikan sehingga dapat mendukung kinerja jasa pendidikan yang berkualitas. 
4. Mempertahankan karyawan terbaik. Selain merekrut karyawan sekolah yang tepat, melatih dan mengembangkan karyawan sekolah untuk menyampaikan kualitas jasa pendidikan, menyediakan sistem pendukungan yang dibutuhkan, sekolah harus mempertahankan karyawan terbaik. Jumlah karyawan sekolah yang keluar, kepuasan pelanggan jasa pendidikan, semangat kerja karyawan sekolah, dan kualitas jasa pendidikan dapat tercermin pada tingkat perputaran karyawan sekolah. Oleh karena itu, sekolah perlu menerapkan strategi pemasaran internal jasa pendidikan untuk memelihara karyawan terbaiknya, antara lain sebagai berikut.

1. Melibatkan karyawan sekolah dalam aktivitas penyusunan visi sekolah, dengan memberi pemahaman kepada karyawan sekolah bahwa pekerjaan yang dilakukan sesuai dengan kerangka kerja organisasi dan sasaran sekolah sehingga tetap bertahan di sekolah.

2. Memperlakukan karyawan sekolah sebagai pelangan jasa pendidikan, dengan melakukan riset pemasaran internal jasa pendidikan secara berkala untuk menilai kebutuhan dan kepuasan pelanggan jasa pendidikan serta memberikan manfaat dan kualitas kehidupan yang layak bagi pelanggan jasa pendidikan.

3. Mengukur dan memberikan penghargaan untuk pelaku jasa pendidikan terbaik, dengan meyusun sistem remunerasi sejalan dengan visi sekolah dan hasil kerja yang dicapai karyawan sekolah dan mempromosikan karyawan sekolah yang

5. Operasi

$$
\begin{aligned}
& \text { berprestasi baik. } \\
& \text { Operasi }
\end{aligned}
$$

Dalam bidang operasi, yang dapat dilakukan oleh SMA Nusantara adalah:

a. Memastikan bahwa sistem manajemen mutu yang diterapkan berjalan dengan efektif sehingga menghasilkan jasa yang berkualitas.

b. Melakukan audit sekolah yang berkesinambungan untuk mengetahui keseluruhan yang terjadi di dalam perusahaan.

c. Memperbaiki kualitas jasa SMA Nusantara terutama pada lingkungan belajar yang kondusif serta melokalisasikan beberapa fasilitas yang ada.

d. Proses jasa pendidikan adalah unsur-unsur struktural jasa pendidikan yang dapat digunakan untuk menentukan posisi strategis sekolah, karena setiap proses jasa pendidikan merupakan perpaduan antara kompleksitas proses jasa pendidikan dan perbedaan proses jasa pendidikan. SMA Nusantara harus melakukan perubahan dari seluruh kompleksitas atau perbedaan proses jasa pendidikan untuk menunjukkan satu dari empat arah strategi proses jasa pendidikan:

1. Mengurangi perbedaan

2. Meningkatkan perbedaan

3. Mengurangi kompleksitas

4. Meningkatkan kompleksitas

\section{DAFTAR PUSTAKA}

Borza, Anca; Bordean, Ovidiu (2008).Journal International Conference Proceedings.Jun 11-Jun 14, 2008. Implementation of SWOT analysis in Romanian Hotel Industry.An Enterprise Odyssey.diakses pada 15 November 2013; ProQuest Research Library

Cox, Marcus Z., Josh Daspit, Erin McLaughlin, dan Raymond J. Jones III. (2012). Journal of Business Strategies.Strategic Management: Is It An Academic Discipline, diakses pada 23 Mei 2013; ProQuest Research Library

David, Fred.R. (2009). Manajemen Strategis, Edisi dua belas, Salemba Empat, Jakarta.

Dewanti, Retno. (2008). Kewirausahaan, Mitra Wdia Media, Jakarta. 
Dyck, B \& Neubert, M.J. (2009). Principles of Management. South-Western: CengageLearning.

Lesmana, R. (November 2019). Analisis Strategi Bersaing PT Dwi Perkasa Mobiltama Pamulang untuk Meningkatkan Penjualan. JIMF Forkamma Vol 3 No 1, 1 - 12.

Mudrajad, Kuncoro. (2008). Strategi Pengembangan Pasar Modern dan Tradisional.Kadin Indonesia.

Nazir, Moh. (2005). Metode Penelitian, Ghalia Indonesia, Bogor.

Nigel F. Piercy (2010). Journal of Business \& Industrial Marketing 25 / 5 2010. Evolution of Strategic Sales Organizations in Business-to-business marketing.diakses pada 20 Desember 2013; ProQuest Research Library

Sunardi, N., \& Lesmana, R. (2020). Konsep Icepower (Wiramadu) sebagai Solusi Wirausaha menuju Desa Sejahtra Mandiri (DMS) pada Masa Pandemi Covid-19. JIMF (Jurnal IImiah Manajemen Forkamma), 4(1).

Ormanidhi, Orges; Stringa, Omer (2008). Journal Business Economics.Porter's Model of Generic Competitive Strategies. July 2008; 43, 3; diakses pada 29 Mei2013; ProQuest Research Library

Pearce II. John A dan Robinson, Richard (2008). Manajemen Strategis - formulasi, implementasi, dan pengendalian. Edisi 10. Salemba Empat, Jakarta.

Rangkuti, Freddy. (2013). Teknik Membedah Kasus Bisnis: Analiis SWOT. Cara Perhitungan Bobot, Rating, dan OCAI.PT. Gramedia Utama, Jakarta.

Robbins, S.P. \& Coulter, Mary. (2011). Manajemen. PT. Indeks Kelompok Gramedia, Jakarta.

Solihin, Ismail. (2009). Pengantar Manjemen. Erlangga, Jakarta.

Sunyoto, Danang. (2013). Manajemen Pemasaran (Pendekatan Konsep, Kasus, dan Psikologi Bisnis). PT. BukuSeru, Jakarta.

Suryana, (2008). Kewirausahaan: Pedoman Praktis: Kiat dan Proses Menuju Sukses, Edisi Keempat, Penerbit: Salemba Empat, Jakarta.

Tangkas Udiono (2010). Analisa dan perancangan system informasi akutansi Penjualan (point of sales) pada koperasi karyawan Bina Nusantara. Volume 01. December 2010

Umar, Husein. (2008). Strategic Management in Action. Cetakan ke lima. PT. Gramedia Pustaka Utama, Jakarta.

Wardani, M. A. (2017). Analisis Daya Saing Dan Faktor-Faktor Yang Memengaruhi Ekspor Ban Indonesia ke Kawasan Amerika Latin. Jurnal Ekonomi dan Kebijakan Pembanguan, Vol 6 No 1, 81 - 100.

Widjaja, Wachidin Anton (2012). Book: The Ary Suta Center. Series on Strategic Management.Kepemimpinan berkewirausahaan: pembentukan kognisi dari kritis menuju keunggulan bersaing. Cetakan Pertama. Januari 2012

Wijaya, David (2012). Pemasaran Jasa Pendidikan. Cetakan Pertama. Salemba Empat, Jakarta. 